\title{
Editorial
}

\section{O financiamento da Ciência para o desenvolvimento da humanidade}

Financing Science for humanity development

Financiamiento de la Ciencia para el desarrollo de la humanidad

O investimento que os Estados realizam em ciência, tecnologia e inovação é fundamental para alcançar patamares de desenvolvimento não apenas econômico, mas também sociais. Há tempos o conceito de desenvolvimento deixou de ser compreendido apenas como crescimento econômico e incorporação de tecnologia, para ser atrelado também às dimensões de bem-estar e sustentabilidade.

A pandemia da COVID-19 serviu para demonstrar como o investimento em ciência, tecnologia e inovação foi imprescindível para o seu enfrentamento. No Brasil, podemos destacar parcerias bilaterais firmadas, com enfoque na transferência de tecnologia, e que está possibilitando a produção de vacina em solo nacional.

A parceria estabelecida entre a biofarmacêutica AstraZeneca e a Fundação Oswaldo Cruz (Fiocruz) permitiu, em março de 2021, o início da produção da vacina contra o coronavírus em larga escala. A incorporação nacional de tecnologia também permitiu a produção nacional do ingrediente farmacêutico ativo (IFA), apontando para uma autonomia nacional na produção do imunizante (1). Já a associação virtuosa entre o instituto Sinovac Biotech e o Instituto Butantan possibilitou, a partir da importação do insumo chinês, a realização da etapa final da produção vacinal no Brasil (envase), com expectativa do Instituto de assumir a produção completa do imunizante, com a transferência completa de tecnologia e a inauguração da sua nova planta fabril.

Contudo, apesar da intensa colaboração científica intra e entre países, os dados relacionados aos investimentos no setor são decepcionantes. Relatório da Unesco (2) publicado em 2021 revela que, no período de 2014-2018, oito em cada dez países destinaram menos de $1 \%$ do seu produto interno bruto (PIB) para as pesquisas,

\footnotetext{
1 Doutora em Saúde Coletiva, Universidade de Brasília, Brasília, Brasil; pesquisadora em Saúde Pública, coordenadora, Programa de Direito Sanitário, Fundação Oswaldo Cruz Brasília, Brasília, DF, Brasil. https://orcid.org/0000-0001-61714558. E-mail: smcalves@gmail.com
} 
demonstrando grande dependência de tecnologias estrangeiras. O Brasil encontra-se ligeiramente acima desse patamar, com um investimento no PIB, para o período relatado, de $1,26 \%(2)$.

Ainda segundo a Unesco, os gastos com pesquisa, em 2018, apresentaram-se concentrados nas regiões do Leste e Sudeste Asiático (40\%); América do Norte (27\%); e União Europeia (19\%). Por outro lado, no período de 2014-2018, as regiões da Ásia Central e América Latina e Caribe não apresentaram aumento nesse gasto (2).

Um outro ponto de alerta que consta no Relatório diz respeito ao aumento no número de pesquisadores sem que haja a respectiva ampliação de verba de pesquisa. Tal fato, associado à redução e até mesmo ao não investimento em pesquisas, tem como consequências a concorrência entre os pesquisadores por financiamento; menor parcela de financiamento para o desenvolvimento de projetos; e perda de potenciais ganhos que poderia ser adquirido com a ampliação desse importante capital humano. Ademais, um ambiente nacional que demonstra desinteresse no apoio à pesquisa e desenvolvimento tecnológico reforçará a migração dos expertos para Estados que ofertam, em seus grandes centros de ciência e tecnologia, melhores condições de trabalho e recursos financeiros voltados ao desenvolvimento de pesquisas, fenômeno conhecido na literatura como brain drain (fuga de cérebros) (3).

Assim é que a comunidade científica brasileira foi tomada de surpresa com a sanção da Lei $n^{\circ}$ 14.220/2021 (4), que retirou do orçamento do Ministério da Ciência, Tecnologia e Inovações quase 600 milhões de reais, comprometendo assim importantes ações de fomento. Sem dúvida, o país observará um retrocesso ou paralisação de relevantes pesquisas, dificuldade de inserção de jovens doutores em redes de investigação; queda no aprimoramento de estudos no exterior; entre outras consequências.

Não se pode olvidar que a Ciência tem um papel decisivo no desenvolvimento econômico e social dos Estados, na redução das desigualdades, na preservação ambiental, e na melhoria da qualidade de vida. Contingenciar o investimento na Ciência é interromper o processo de desenvolvimento e, sem Ciência, não há futuro para a humanidade.

\section{Referências}

1. Fundação Oswaldo Cruz. Vacinas contra a Covid-19. [citado em 20 de out 2021]. Disponível em https://portal.fiocruz.br/vacinascovid19 
2. UNESCO. Relatório de Ciências da UNESCO: A corrida contra o tempo por um desenvolvimento mais inteligente - resumo executivo. Paris: UNESCO Publishing; 2021 [citado em 15 de out 2021]. Disponível em https://unesdoc.unesco.org/ark:/48223/pf0000377250 por

3. Docquier F, Rapoport H. Globalization, brain drain and development. Discussion Paper $n^{\circ}$ 5590. Bonn, Germany: Institute for the Study of Labor (IZA); 2011 [citado em 21 de out 2021]. Disponível em: https://ftp.iza.org/dp5590.pdf

4. Brasil. Lei $n^{\circ}$ 14.220. Abre aos Orçamentos Fiscal e da Seguridade Social da União, em favor de diversos órgãos do Poder Executivo, crédito suplementar no valor de R\$ 690.000.000,00, para os fins que especifica. Diário Oficial da União, nº 199 [retificação]; 21 de outubro de 2021 [citado em 22 de out 2021]. Disponível em https://pesquisa.in.gov.br/imprensa/jsp/visualiza/index.jsp?jornal=515\&pagina=6\&data=21/1 $\underline{0 / 2021}$

Alves SMC. O financiamento da Ciência para o desenvolvimento da humanidade. Cadernos Ibero-Americanos de Direito Sanitário. 2021 out./dez.;10(4):08-10.

https://doi.org/10.17566/ciads.v10i4.858 